\title{
SAW Sensor Technology and Its implementation and application in Electric Power Temperature Measurement
}

\author{
Weihai Song $^{[1]} \quad$ Jie Tong ${ }^{[2]}$ Dongfang Wang ${ }^{[3]}$ \\ (Shandong agriculture and engineering university Jinan 250100; :China Electric Power Research \\ Institute, Beijing 100080; Salisense Technology Co., Ltd ,Nantong 226019 )
}

Keywords: SAW, sensor, temperature, smart grid, power switch cabinet

\begin{abstract}
This article firstly has an overview of Surface acoustic wave (SAW) sensor technology, including its history, principle, compare of resonate type and delay-line type. SAW technology is also compared with other temperature sensor technologies. To meet the temperature detecting requirement, we have developed a resonant type SAW temperature sensor product. The product has been used in practical engineering. Some engineering problems are still to be resolved in future.
\end{abstract}

\section{INTRODUCTION}

In power accidents, equipment explosions or burnings occurring from over-heating account for a large proportion. The heating parts are mainly all kinds of contacts, connectors, plugs and rotating parts of power equipments, and the main causes are aging, corrosion, loose, overload and poor ventilation etc. Before the accidents, these sites often have phenomenon of abnormal temperature rising. So preventing the accidents by monitoring temperature of these sites are of great importance.

In recent years, the concept of smart grid is proposed and developed rapidly. An important feature of the smart grid is informational and automatically, which means acquiring the status information efficiently and automatically. This trend of development promotes the application of online monitoring technology in the power grid. Power facilities are unmanned supervised gradually. In these new application technologies, surface acoustic wave (SAW) sensing technique has become a bright spot.

SAW was originally found by the British physicist Rayleigh in 1880s. During his research of seismic wave, he found a wave focusing and propagating in the surface of the earth. In 1965, American R. M. White and F. M. Voltmov invented interdigital transducer (IDT), which can excite SAW in the piezoelectric material. This accelerated the development of SAW technology, and many kinds of SAW devices with different characteristics appeared[1]. Research and development of SAW sensor began in 1980s. At first, the researchers found that external factors (temperature, pressure, magnetic field, electric field, a gas) will affect the propagation characteristics of SAW, and to study the relationship between these effects and external factors. According to these relationships, a variety of structure were designed for various physical and chemical measurements.

The SAW sensor is of two characteristics, passive (no need for battery powered) and wireless reading i.e., so it is also known as the passive wireless sensor. In the past ten years, as the technology matures, some types of SAW sensors have been in the market application stage, such as the TempTrackr temperature sensor of sengenuity company in USA[2] , the car tire pressure sensor of Transense company in British, the individual chemical agent alarm (JCAD) in U.S. Army. The sengenuity's TempTrackr is the first SAW sensing product that is used in power temperature measurement. Due to its unique advantages of passive and wireless, it has been paid intense attention to, since it entered the Chinese market. And follow-up study is also appearing at the same time. Now, Chinese SAW temperature sensor products are gradually maturing, and some have passed the certification of the authority of the state agency. 


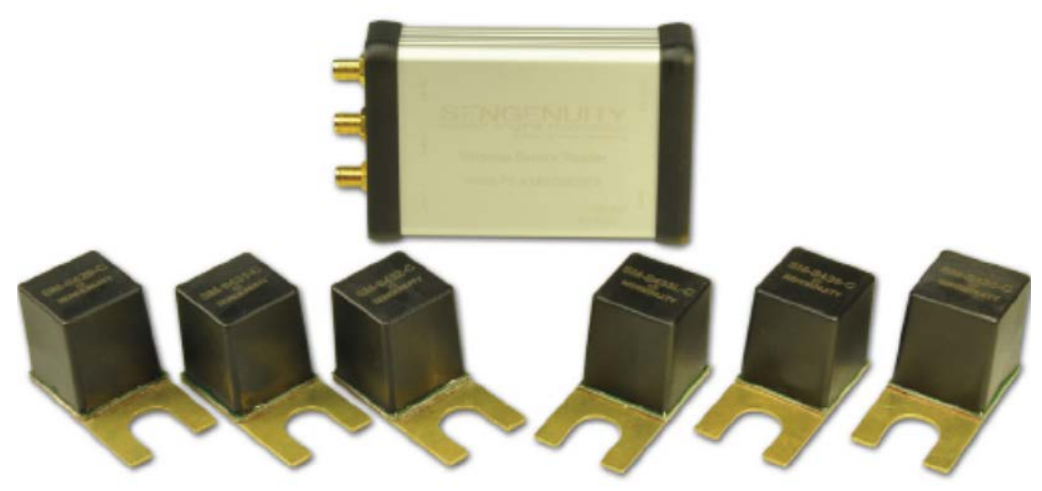

Figure 1 sensor product of Sengenuity company

This article will first have an overview of SAW sensor technology. Two type of SAW sensor types------ resonant and delay line------ are compared both in theory and examinations. Then the resonant type of SAW temperature technology will be discussed in details, which is very suitable for power switch cabinet.

\section{SAW SENSOR PRINCIPLE}

A SAW device is manufactured with semiconductor IC technology, such as deposition and lithography, to form specific shape and size of metal (aluminum, et. al.) film on a piezoelectric substrate material. Piezoelectric material selection, intervals of the IDT fingers and reflecting gates, et. al. determine the characteristics of the SAW device, including operating frequency, quality factor, parasitic suppression, insertion loss and sensitivity coefficient [3].

According to the device structure and signal characteristics, SAW sensor devices can be divided into the delay line type and resonant type, as shown in figure 2 and figure 3. For the delay line type, the reflectors distribute at different position to one side of the IDT. Due to the different positions, the reflectors reflect the acoustic signals with different delay time. The delay time can also be affected by some environmental factors. By detecting the alternation of the delay time, measurement to environmental factors can be realized. The positions of the reflectors can also serve as ID function, which is the principle of RFID [4]. For the resonant type, the reflectors distribute periodically on both sides of the IDT, forming a resonant cavity to the surface acoustic wave signal with certain frequency. So the return signal is a resonance signal. The resonant frequency is not only determined by the size, but also influenced by environmental factors. By detecting the alternation of the resonant frequency, sensing can be realized [5].
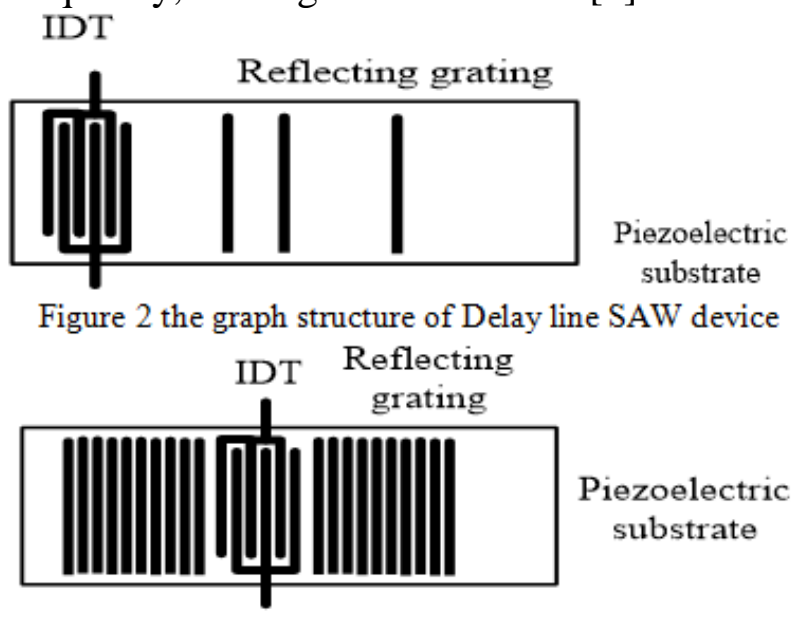

Figure 3 the Graphical structure of resonance type SAW device

If an antenna is connected to the IDT, it becomes a wireless SAW sensor which can receive and 
reflect electromagnetic wave. The electromagnetic signal is received by the antenna and converted into acoustic signal by the IDT. The acoustic wave propagate along the substrate, and is reflected by the reflectors back to the IDT, and then is reconverted into an electrical form and re-transmitted by the antenna $[4,6]$. As can be seen, the whole process is completely passive, i.e. no power supply is needed. So the SAW wireless sensor is also called the passive wireless sensor.

The SAW wireless sensor must operate with a special reader. In fact, the SAW wireless sensor in real concept is a system that is composed of SAW devices and a reader that operates with the principle of radar. The two units exchange information by electromagnetic wave. And according to the two types of the SAW device, the reader also have two types: Frequency Modulated Continuous Wave (FMCW) reader type [7] and pulse radar type. An obvious difference is that a FMCW reader sweeps frequency in a saw-tooth form during a reading, yet a pulse reader only sends a certain frequency pulse.

No matter what type the SAW senor systems are, their working processes are similar. The reader transmits electromagnetic signal at first and the SAW sensor receives the signals and then returns electromagnetic signal back to the reader. By detecting the returned signals, sensing is realized.

\section{Comparison of two type of SAW sensor systems}

Most SAW sensor products adopt resonant type. This is partially because the pulse-radar reader is simpler in principle and is cheaper in cost. We tested the two types in different environments. If put a resonant one in a metal box, the received sensor signals were strengthened significantly, even exceeded the upper limit. If place a delay-line type in a metal box, it worked worse than in open environment. This indicates that resonant type is the best option for switch cabinet.

The FMCW reader sweep frequency for tens of MHz bandwidth, this indicates that the system doesn't rely on a signal frequency. So in theory, it has better anti-interference performance. On the other hand, if a SAW sensor system has to work at a band above $1 \mathrm{GHz}$, then the delay line type is preferable, because it is hard to manufacture a SAW resonator at so high frequency band. Table 1 is a compare of the two types.

Table 1 Comparison of resonant and delay-line SAW sensor type

\begin{tabular}{|l|l|l|}
\hline SAW sensor type & Delay line & Resonant \\
\hline Device insertion loss & About 30 40 dB & Generally less than 3 db \\
\hline Identify ways & $\begin{array}{l}\text { Code division multiple } \\
\text { access }\end{array}$ & $\begin{array}{l}\text { Frequency division multiple } \\
\text { access }\end{array}$ \\
\hline $\begin{array}{l}\text { Working mechanism of } \\
\text { the reader }\end{array}$ & FMCW & Pulse mode \\
\hline Suitable frequency band & Above 1 GHZ. & Hundreds of MHZ \\
\hline Working bandwidth & Wider & Narrower \\
\hline Anti-interference ability & stronger & Weaker \\
\hline $\begin{array}{l}\text { Suitable operating } \\
\text { environment }\end{array}$ & Open environment & Enclosed metal environment \\
\hline
\end{tabular}

\section{Comparison with other temperature sensor technology}

The traditional power temperature measuring method is artificial infrared inspection, the disadvantage of this approach is:

Detecting is not in real time ;

Probability of mistake or miss test is high;

Easy to be affected by dust and weather;

The part to detect must be in sight;

Cost is high.

For the above reasons, it is necessary to use on-line temperature detecting technology. At present, there are four main table 2 is the comparison of several kinds of technology. 
Table 2 online power characteristics of temperature measurement technology

\begin{tabular}{|l|l|l|}
\hline Name & Advantage & Disadvantage \\
\hline Optical fiber & $\begin{array}{l}\text { Can be measured } \\
\text { distributely }\end{array}$ & $\begin{array}{l}\text { 1) Cable is difficult to install; } \\
\text { 2) Easy to break; } \\
\text { 3) Expensive; } \\
\text { 4) With risk of creepage. }\end{array}$ \\
\hline $\begin{array}{l}\text { Active } \\
\text { wireless }\end{array}$ & $\begin{array}{l}\text { 1) Wireless } \\
\text { 2) Long distance. }\end{array}$ & $\begin{array}{l}\text { 1) Need to change the battery regularly; } \\
\text { 2) Operate below } 85^{\circ} \mathrm{C} \text {; } \\
\text { 3) Risk of battery leakage or explosion. }\end{array}$ \\
\hline $\begin{array}{l}\text { Powered by } \\
\text { current } \\
\text { transformer }\end{array}$ & $\begin{array}{l}\text { 1) Wireless; } \\
\text { 2) Long distance. }\end{array}$ & $\begin{array}{l}\text { The equipment has a working current to be measured } \\
\text { 1) Input current of the CT must not out of a certain } \\
\text { range; } \\
\text { 2) large size; } \\
\text { 3) Operate below } 85^{\circ} \mathrm{C} \text {. }\end{array}$ \\
\hline SAW & $\begin{array}{l}\text { 1) Wireless } \\
\text { 2) Completely passive; } \\
\text { 3) Small size; } \\
\text { 4) Thermostable. }\end{array}$ & Wireless distance within about 10 meters \\
\hline
\end{tabular}

In summary, relative to other online temperature measurement, SAW technology has the advantage as follows:

Safe and reliable.

The SAW sensor does not destroy insulation, and does not bring risk of creepage. The SAW sensor is really passive sensors, i.e. without battery. And it has no ICs and circuits inside, so it is thermostable. Risk like battery leakage or explosion does not exist.

Easy to maintain

The SAW sensor is small in size. Made from piezoelectric material, It is long life.

Of course, as a kind of passive sensor, its wireless reading distance is restricted, due to its weak signal. But a distance of a few meters is sufficient for high voltage insulation. Combined with cable or wireless communications, the temperature data can be transmitted to any specified position.

\section{Design and impletion of a resonant type SAW sensing system}

As above dimensioned, the resonant saw sensor is very suitable for the power switch cabinet which is lack of effective temperature-detecting method. So in the past a few years, we have developed such a product. We have also accumulated some experience during its applications.

The resonant SAW temperature sensor has a resonant frequency that alternates linearly according to the temperature. So a resonant SAW sensor must occupy a certain frequency band in the whole temperature range. The bandwidth is determined by the temperature coefficient and the temperature range. Obviously, these factors must be decided carefully. Before the system be designed, two general problems must be solved at first:

1) the operating frequency band. Besides technical factors, policy factors must also be taken into account. It is reasonable to choose the amateur radio frequency band of $430 \sim 450 \mathrm{MHz}$, and restrict wireless power of the reader [8].

2) the selection of piezoelectric materials. Some kinds of piezoelectric materials can be used for the SAW sensor device, such as quartz, LiNbO3, LiTaO3 and so on. Even for the same material, different cutting angle brings different characteristics. The ideal piezoelectric material should be of a unique temperature coefficient in the whole range and the coefficient should also be appropriate, i.e. not too large or small. Large coefficient will improve the measuring accuracy, yet will occupy wider frequency bandwidth. On the other hand, too small coefficient will decrease the measuring accuracy.

Two key problems must be well solved in the development of the product:

1) SAW resonator with high quality factor and low parasitic. Experiments indicate that, to acquire good sensor signal, the SAW resonator should be of a unloaded quality factor (Q) more than 8000 (room temperature). Besides, the parasitic resonances of the SAW resonator should be as low 
as possible. Parasitic resonances may disturb the sensor signal, as will cause temperature measuring errors.

2) accurate and Reliable signal analysis. In theory, to detect the frequency of wireless signal is not difficult, but the SAW sensor's signal is both weak and short in time. Experiments indicate that the signal can has an amplitude not larger than one millionth milliwatts. How to quickly and accurately obtain the sensor signal's frequency has to be carefully studied. Figure 4 is the picture of the SAW sensor. The left in the picture is the SAW device and the right is the sensor. Totally 6 SAW sensors with different frequency have developed. Figure 5 is radar reader which is of four antenna interfaces, 1 power interface and 1 data interface. Equipped with antennas, the reader can acquire temperature of the $6 \mathrm{SAW}$ sensors 2 meters away, and transmits the temperature data by a RS485 cable, as shown in figure 6.

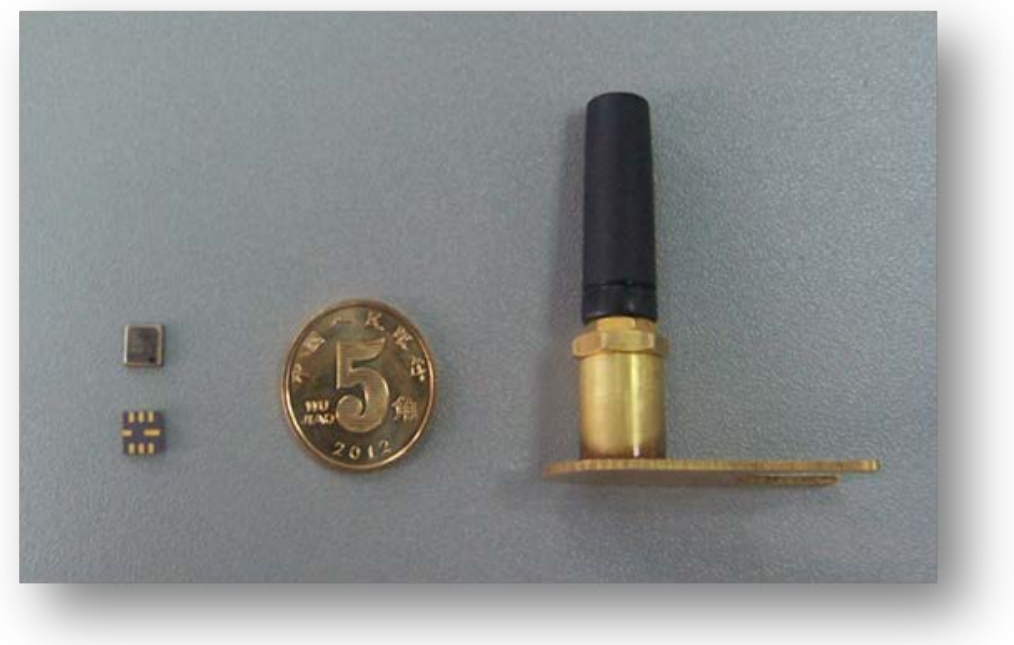

Figure 4 SAW sensor device(left) and wireless SAW sensor (right)

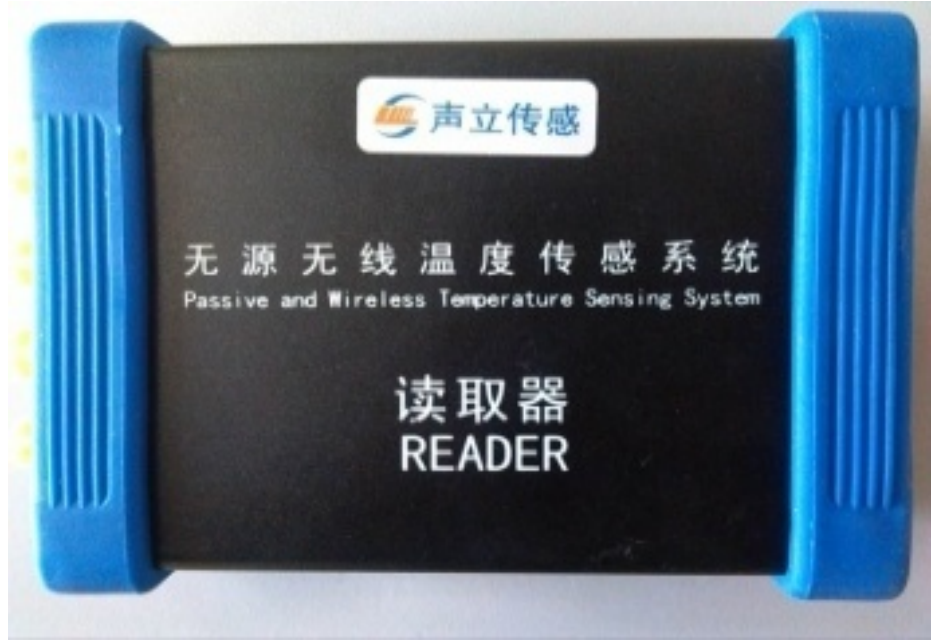

Figure 5 SAW senor reader

\section{Engineering application}

Figure 6 is a schematic diagram of the SAW temperature monitoring system. In order to be suitable for power switch cabinet, the antenna and reader are connected by a cable, and the antenna has a strong magnet at its bottom which can fix the antenna on the iron shell. Generally, the reading distance of $0.2 \sim 2$ meters is sufficient for application. If long distance is needed, there are three ways: 1) increase the reader transmitting power; 2) replace the reader antenna with a high gain one; 3 ) replace the sensor antenna with a high gain one. But the high gain antenna has a large size which maybe unaccepted by the environment. 


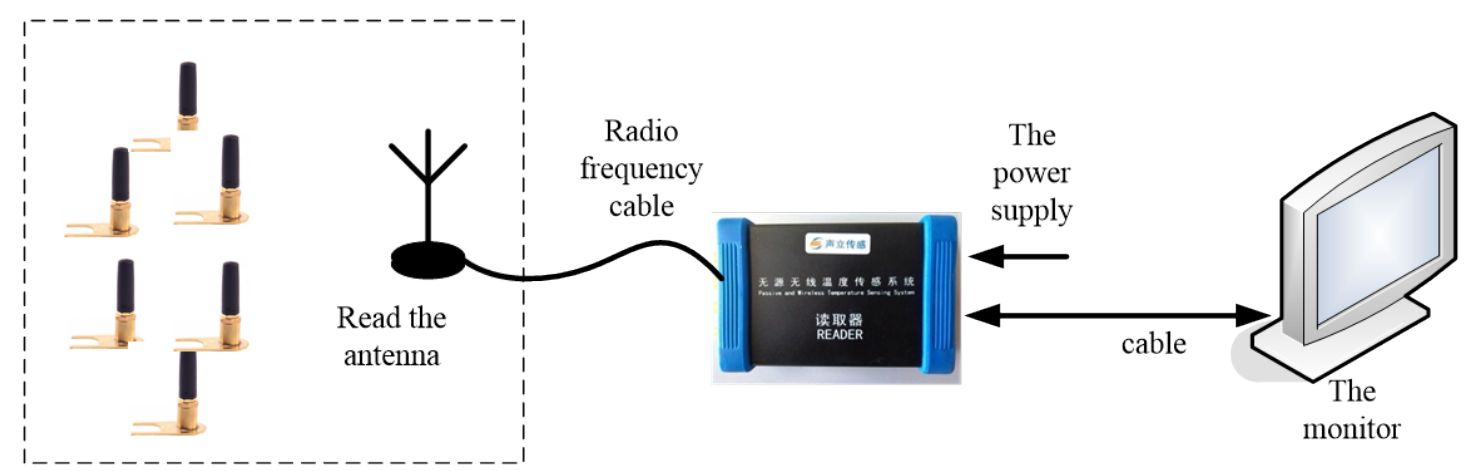

Figure 6 SAW temperature monitoring system diagram

Figure 7 and figure 8 are the photos taken from the engineering field. Figure 7 shows the installed 3 sensors and a reading antenna. The sensors are fixed behind the static contactors of the switch cabinet, and are used to detect the contactors' temperature. The antenna is installed on the wall of cabinet. The reader can be installed freely, for example mounted on the low voltage side of the switch cabinet, as shown in figure 8.

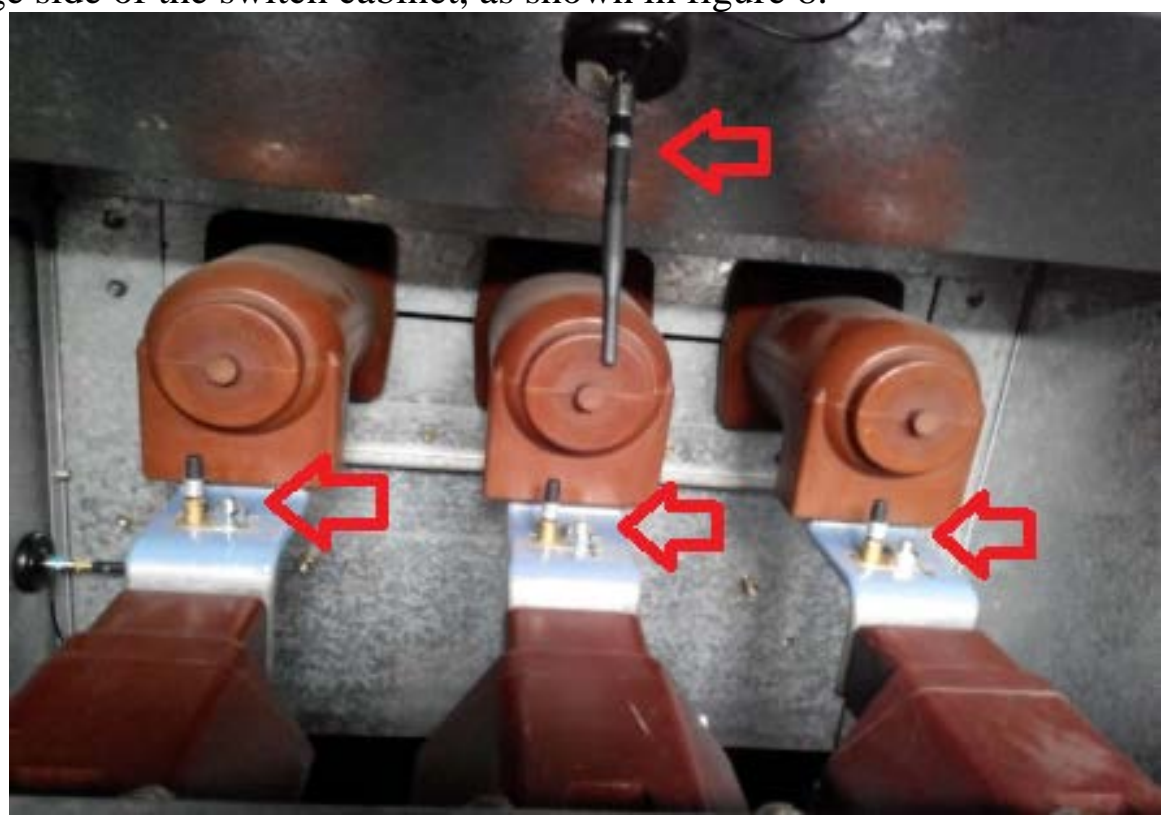

Figure 7 Installation of the sensors and reading antenna

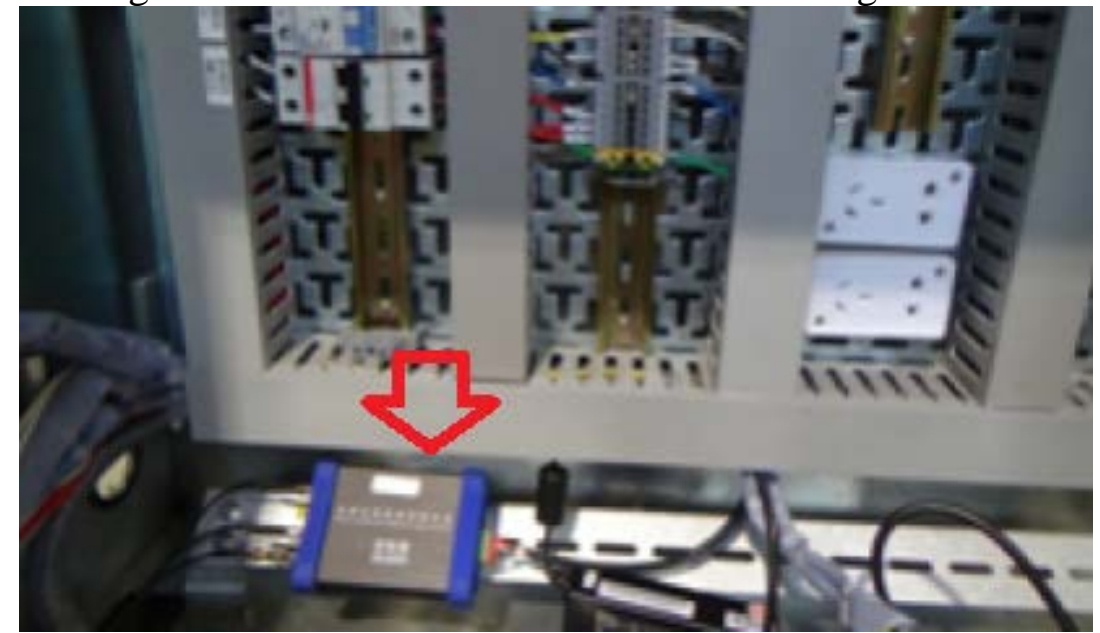

Figure 8 Installation of the reader

Now most engineering is technical reconstruction. The power is only turned off for only a few hours, and the tens of the SAW temperature sensing systems are to be installed. This is a great challenge. Besides the power switch cabinet, there are other kinds of power equipments require temperature detection. So It is necessary to develop more convenient and various installation structures. 
The power equipments do not leave rooms for the SAW sensors to install. This also brings difficult to the installation engineering. As power equipments for the smart grid, it is necessary to install the SAW sensors in their layout and manufacture stage.

\section{Conclusion}

Being wireless and passive sensors, SAW sensors is safer and more reliable. So they are suitable for power equipments. On the other hand, there are some engineering problems to be solved. This is mainly because the various installation requirements. It is an important work in the future. On the other hand, as equipments for the smart grid, it is necessary to install the SAW sensors in the layout and manufacture stage of the power equipments..

\section{REFERENCES}

[1] P.V. Wright, A Review of SAW Resonator Filter Technology, IEEE Ultrasonics Symposium, 1992, page 29 37.

[2] Product manuals of Sengenuity, TempTrackr_Wireless_Multipoint_System_Kit-6.

[3] Alfred Pohl, A Review of Wireless SAW Sensors, IEEE transactions on Ultrasonics, Ferroelectrics and Frequency Control, vol. 47, No. 2, march 2000, page 317 331.

[4] Victor P. Plessky, Leonhard M. Reindl, Review on SAW RFID Tags, IEEE Transactions on Ultrasonics, Ferroelectrics, and Frequency Control, vol. 57, no. 3, March 2010, Page 654 668.

[5] Leonhard Reind, et. al., Theory and Application of Passive SAW Radio

Transponders as Sensors, ieee transactions on ultrasonics, ferroelectrics, and frequency control, vol. 45, no. 5, september 1998, page 1281 1292.

[6] Peter Scholz, et. al., Low-cost Transceiver Unit for SAW-Sensors Using

Customized Hardware Components, IEEE Ultrasonics Symposium, 2006, page 949 952.

[7] 《中华人民共和国无线电频率划分规定》, 2010 年版本。 